\title{
OVERVIEW OF PROPOSED ACCELERATOR-DRIVEN SPALLATION TARGET APPLICATIONS*
}

\author{
Gregory J. Van Tuyle \\ Department of Advanced Technology \\ Brookhaven National Laboratory \\ Upton, New Yark 11973 \\ John R. Ireland \\ Technology and Safety Assessment Division \\ Los Alamos National Laboratory \\ Los Alamos, NM 87545
}

\begin{abstract}
With the rapid development of particle accelerator tochnologies during the Strategic Defense Initiative (SDI) of the 1980s and the severe institutional and political challenges faced by the nuclear reactor community, there has been increasing interest in the use of particle accelerators to fulfill some nuclear missions in the U.S. and abroed. This paper describes the enabling technologies, as well as proposed applications for neutron sources (research applications), tritium production (defense), production of other special isotopes for medical or space-power applications, and waste actinide transmutation.
\end{abstract}

\section{INTRODUCTION}

Nuclear reactor technology and particle accelerator technologies have been developed along parallel paths for several decades, with one of the few similarities being the capacity to produce neutrons via fission (reactors) or spallation, the latter oceurring when high energy particles slam into target materials. One of the earliest proposed hybrid applications involved using spallation neutrons to supplement the fission process in accelerator-driven breeder reactors (Kouts and Steinberg, 1978). More recently, advances in accelerator technologies, fueled largely by the Strategic Defense Initiative of the 1980s, have made viable much larger applications of hybrid technologies. In such applications, one uses the neutrons produced during spallation events, induced by driving charged particles into heavy targets, either to produce or destroy materials that would have previously been produced and/or destroyed in nuclear reactors. In some instances, these spallation neutrons are

*This work was performed under the auspices of the U.S. Department of Energy. multiplied in a target containing actinides in some subcritical configuration.

Once one assumes the availability of large quantities of spallation neutrons, a wide array of potential applications becomes readily apparent, based in large part on missions previously undertaken using nuclear reactors. Given the recent political difficulties in building nuclear reactors in the U.S. for any purposes, it is indeed tempting to use accelerators for all missions traditionally fulfilled by the reactors. However, it is essential for the proponent of accelerator-target applications to develop technically credible reascons for moving away from reactor solutions that could, in some cases, be simpler and cheaper. In many of the applications proposed, the justifications are generally based on significant environmental, safety, and/or economic or operational advantages.

\section{THE ENABLNG ACCRLERATOR} TECHNOLOGIES

A primary research tool for physicists, accelerators have advanced from the earty cyclotrons to highly complex superconducting linacs and rings (e.g., synchrotrons) (Humphries, 1986). Of greatest interest to the applications discussed here are the linear accelerators, or "linacs". That is becuuse the "ring" machines, which economize on length by sending the particles through multiple passes through the same acoelerating field, cannot currently produce currents much higher than a few milliamps. Further, the energy required to continuously bend the beam is significant, making it difficult to match the efficiency of a linac. The economics are such that if one needs a very few megawatts in the beam, a circular machine might be the right solution, especially if the goal is to minimize the capital cost. In contrast, if several tens of megawatts of beam power are required, a high current linear accelerator (linac) is the clear choice. 
While several applications of such large proton linacs are under discussion, the most mature design is the one associated with the Accelerator Production of Tritium (APT) (Wangler, et.al., 1990). The tritium production requirements have shifted several times, which has shifted the linac beam requirements. The largest such machine in the recent history of APT is illustrated in Figure 1 (Lawrence, 1994). In this case the $200 \mathrm{MW}$ of beam power requires two "legs" at the front-end of the machine, since it would be difficult to drive more than $100 \mathrm{~mA}$ through the Radio Frequency Quedruple (RFO). Both the Coupled Cavity Linac (CCL) and the Dritt Tube Linac (DTL) portions require only modest engineering efforts. The funnel is unproven, although accelerator specialists believe this beam combiner is technically feasible.

There are many factors involved in determining machine efficiency. However, with a beam power of $130 \mathrm{MW}$, a $100 \%$ efficient machine would still require $130 \mathrm{MWe}$ from the electric grid. By keeping the current high (a hundred $\mathrm{mA}$ is very high), the designers minimize the overhead losses in the cavities. However, there remains losses in the tubes used to convert AC power to RF power ("klystrons" or "klystrodes") as well as losses in the AC and RF power systems. Once the power needed to operate the target systems and coolant systems are factored in, the system electricity conversion efficiency is approximately $30 \%$. The tritium requirements currently envisioned need close to $430 \mathrm{MWe}$ power input from the grid.

There are options to reduce the power consumption, including options to use more efficient AC to RF tubes, as well as options to improve the target efficiency (less beam power needed). However, the most intriguing option involves superconducting cavities (see Figure 2), and possibly superconducting magnets. Niobium cavities have been used in electron accelerators such as the Continuous Electron Beam Accelerator Facility (CEBAF) and in heavy ion accelerators, but have not yet been demonstrated in proton wocelerators. The utilization of superconducting technology alone would likely boost the machine efficiency to around $40 \%$, and the development of more efficient tubes and target modules could push the efficiency toward $50 \%$.

\section{SPALLATION PHYSICS}

"Spallation" refers to nuclear reactions that develop when high energy particles (above $100 \mathrm{MeV}$ per nucleon), such as protons, neutrons, pions, muons, or deuterons, interact with an atomic nucleus. At energies above the DeBroglie wavelength of the incident particle, the particle interacts with individual nucleons within the nucleus. The initial collision between the incident particle and the target nucieus leads to an "intranuclear cascade", wherein individual nucleons or small groups of nucleons are ejected from the target mucleus. Should the incident particle energy exceed a few $\mathrm{GeV}$ per nucleon, the target nucleus could be "fragmented". Subsequent to the cascade process, excited nuclei "evaporate" off nucleons to reach the ground state. Most of these nucleons are neutrons, and many of the "spallation neutrons' result from the evaporation process, and are thus emitted isotopically, which is important in the target design (Russell, et.al., 1994).

The spallation process is illustrated in Figure 3 which shows both the cascade process and the evaporative phase. Also shown is the high-energy fission that can occur with heavy target materials such ss lead and tungsten. Should actinides, such as uranium or thorium, be used as target materials, fission could also be triggered by low energy neutrons.

The estimated numbers of spallation neutrons (per proton) produced in five candidate materials as a function of incident proton coergy are shown in Figure 4 (Russell, et.al., 1994). In general, the greatest production is in the actinides, even without taking into account the multiplication from fission. However, most proposed targets do not use actinides so as to avoid high level waste and mixed-waste issues and other instiutional and safety concerns. Instead, tungsten, lead, or tantalum are often chosen. Of the three, ungsten is the most efficient producer, although one must design the target carefully to minimize parasitic capture of the neutrons in the tungsten. Lead has much lower neutron absorption, but its low melting temperature is a drawback.

\section{NEUTRON SPALLATION SOURCES}

A direct epplication of an eccelerator-driven target is as a source of spallation neutrons. Such neutron sources differ from research reactors, such as the High Flux Beam Reactor (HFBR) at BNL, in that the spectra include some very high energy neutrons and that there may be a time-variant nature to "pulses" of neutrons (Klein, 1994).

The recent decision by the U.S. Congress to discontinue work on the Advanced Neutron Source (ANS) (Selby, ct.al., 1994), raises scme interesting issues regarding spallation sources. First, in order to achieve a high neutron density, the Oak Ridge designers had increased the power to a level where the design of coolant and safety systems was very challenging. For comparison, the energy produced in the reactor to free up a neutron is about $200 \mathrm{MeV}$, whereas spallation neutrons can be provided for about 30 to $50 \mathrm{MeV}$ apiece. Thus, a much higher neutron density could be achieved with fewer power density concerns.

A second item for comparison is total neutron production, where a spallation source driven by a $100 \mathrm{MW}$ beam could rival a large research reactor in terms of neutron production. (A more typical assumption, however, is for facilities having 1 to $5 \mathrm{MW}$ of beam power).

One candidate spallation target, developed by BNL (Todosow and Ludewig, 1994), is shown in Figure 5. In order to absarb $5 \mathrm{MW}$ of beam power in a very compact target, tungsten particles $(2 \mathrm{~mm}$ diameter) are packed into closed-packed beds and cooled directly by heavy water. In order to minimize parasitic capture in the 
tungsten and minimize leakage out to experimental facilities/ instruments, very little neutron moderation is provided in the tungsten region.

\section{ACCELERATOR PRODUCTION OF TRITIUM (APT)}

The production of tritium using accelerators is based on a two step process, i.e., the production of neutrons in the "Source" or "Target" region, and the use of those neutrons in a surrounding "blanket" region (Cappiello, et.al., 1994). With over $100 \mathrm{MW}$ of beam energy, the proton beam must be expanded to reduce the power density on the target to manageable levels. This is accomplished using a series of quadrupole and octupole magnets called a "beam expandex". The distribution of protons on the target surface can be made fairly uniform and spread over a larger area. In the case of APT, the beam "spot" is about $14 \mathrm{~cm}$ across and $1.4 \mathrm{~m} \mathrm{high}$, and impects on 10 rows of stainless steel "ladders", as shown in Figure 6. Within each of the ladder elements are hundreds of $1 / 8^{\text {" diameter }}$ tungsten pins, which are cooled using heavy water. With the hard spectrum, the narrow ladder, and the spacing between the rows, most of the neutrons escape the tungsten before capture.

The APT blanket region includes four material components: lead (further spallation production, plus $(n, 2 n)$ reactions), light water (neutron moderation and heat removal), aluminum (structure with minimal neutron capture), and either lithium-6 or helium-3. When either lithium-6 or helium-3 capture a neutron, tritium is produced, and both have large neutron absorption coefficients at thermal energies. In the case of helium-3, the system is gaseous, and the tritium produced is continuously extracted. When lithium is used, it is in the form of solid lithium aluminum, clad with aluminum. By limiting the lithium-6 enrichment to $50 \%$, it is assured their will be anough lithium-7 to tie up the tritium as lithium tritide. In addition, cool aluminum is an effective barrier to tritium. With lithium ahmimum it is necessary to use batch extraction, whereby a load of rods or plates must be removed regularty (perhaps annually) and then heated in furnaces to extract the tritium (exactly like the Savannah River Process).

A key step in minimizing the parasitic capture of neutrons in the tungsten region is to include a "decoupler" region along the inside of the blonket. The belium-3 or lithium-6 content in this inner-most (adjacent to the tungsten) region is high, making the region "black" to any potentially re-entrant neutrons. Helium-3 is nearly ideal in this respect, since fast protons or neutrons pass virtually unimpeded, but thermal neutrons face a huge neutron absorption cross-section (5000 barns).

\section{PRODUCTION OF SPECIAL ISOTOPES}

In 1992 report the GAO describes the production and availability of medical isotopes, including those used for both diagnostic and therapeutic applications (U.S. General Accounting Office Report, 1992). While at that time DOE sold only about $\$ 15$ million of the roughty $\$ 500$ million in isotope sales that year, the GAO stated that
"DOE is considered an important supplier, since most of the isotopes it produces are not otherwise available domestically and same have a limited worldwide backup source for their supply." In addition, the use of radioisotopes is increasing and the availability of an isotopes can impact on the use of that isotope, i.e., if it can be established that an isotope is in demand someone will begin production and marketing activities.

Most of the DOE's medical isotope production has been in aging research reactors or in lincar sccelerators. Generally, the accelerators have been used when protons are required for isotope production However, if no new research reactors are built, one can envision the future use of accelerator-driven spallation targets to produce medical isotopes requiring neutrons.

Another special isotope requirement is for Pu-238, which NASA uses as a long-lived (88 year half-life) power source for deep-space missions. About 15 kgyear is required, which would require an accelerator with a beam power of roughly $10 \mathrm{MW}$. In this case, however, there is an interesting constraint on the design. Since Np237 is the material to be converted, one has to minimize high energy (above $6.8 \mathrm{MeV}$ ) particles and gamma radiation in the blanket region. Otherwise the production of Pu-236 (2.9 year half-life) will exceed a few parts-per-million, making it too hot for NASA's applications (Brager, ctal., 1989). For proctuction in a spallation target blanket, that means placing the neptunium away from the beam (and any direct knock-on particles), and choosing structural materials that can't emit high esergy $\gamma$-rays.

\section{SUBCRTICAL TARGET PHYSICS}

If fissionable materials are used in a spallation target or in a blanket around a spallation target, the number of neutrons can be greatly enhanced. In terms of the effective neutron multiplication factor for the lattice, $k$,

$$
\text { \# fission neutrons = \# source neutrons }
$$$$
\cdot\left|\frac{k}{1-k}\right|
$$

Thus, if the target or blonket is nearly critical at $k=0.95$, there will be 19 fission neutrons produced for each spallation neutron triggering a fission event in the fissile material (Van Tuyle, 1993). When one considers that $a$ single proton could be producing 40 to 50 spallation neutrons (in ectinide targets), there is an enormous amplification that takes place.

The design implications of this multiplication are twofold. First, one can use an accelerator to produce spallation neutrons to supplement and effectively drive a subcritical assembly. This would be desirable if the assembly containod too little fissile material or too much parasitic capture to be critical. The second major implication is one of control. Most nuclear reactors are designed to have reactivity characteristics that will cause the machine to produce less power if an overheating condition develops. The counter-example 
is the Russian RBMK reactor, which, under certain circumstance, cen experience regions of instabilities (positive reactivity feedbacks). The 1986 accident at Chernobyl-4 resulted from this design characteristic, together with a series of ill-advised actions by the plant operators. In the case of a spallation-driven target, one can sut off the beam in a millisecond, and unless the $k$ has reached 1.0 , the subcritical assembly will shut down quickty once deprived of spallation neutrons.

\section{ACCELERATOR-DRIVEN WASTE BURNERS}

Whereas the neutron multiplication discussed above once led to notions of accelerator-driven breeder reactors, most of the current work is in muclear waste burners. This is because the development oflong-lived (geologic) waste repositories has proved difficult and expensive to implement around the world. It is perceived by many that political, institutional, and economical issues are the major obstacles. However, a careful study of the nuclear wastes that must be processed reveals that it is only 1 to $2 \%$ of the waste stream that presents long term disposal problems (Binney, et.al., 1990). Further, most of the problem isotopes can either be fissioned in "waste burners", or can be converted via neutron capture to stable isotopes (see Figure 7). Once one begins to analyze the realities of the nuclear waste problem thusly, the accelerator stands out as an important tool in the conversion process. Further, most concepts are net energy producers because of the fission process.

\section{THE ACCELERATOR TRANSMUTATION OF WASTE (ATW)}

In the terms of objectives and programmatic scope, for accelerator transmutation, the ATW Program at Los Alamos is easily the most ambitious and technically challenging (Bowman, et.al, 1992). Included in the mission are all long-lived problem isotopes, including some cesium and strontium isotopes that are especially difficult to transmute. In addition, while ATW addresses spent commercial nuclear fuel, sister projects at LANL, AcceleratorBased Conversion (ABC) and Accelerator-Driven Energy Production (ADEP), address the conversion (fission) of excess phutonium from retired weapons as well as the creation of a "new" fuel cycle ("Energy Production") based on thorium. In order to transmute all the problem isotopes, ATW also burns the plutonium in the spent fivel, and therefore does not assume the existence of an advanced power reactor running on plutonium.

The ATW Target/Blanket region (sce Figure 8) resembles a pooltype sodium cooled reactor. In fact, it is more closely based on the 1960 s Oak Ridge Molten Salt resctor concepts. In the center of the vessel is a small molten lead spallation target, which is used to convert the proton beam entering through the vessel head into a fairly intense source of neutrons. Various materials, including all the actinides, are contained in the molten salt, with the plutonium content carefully controlled to maintain the desired sub-criticality.

ATW is very ambitious in terms of the technology development required, as well as the number of machines required. Materials, engineering, and chemistry challenges are evident, and there may be issues associated with corrosion, erosion, and possible precipitation of fissile materials. In addition, one would noed about 20 such machines to keep up with the current rate of commercial nuclear waste generation. The net power production from these 20 waste burmers would add about $4 \%$ to the total U.S. electricity production.

\section{THE PHOENT CONCEPT}

BNL's interpretation of the materials in reference Binney, et.al., 1990, which hes been captured in Figure 7, differed somewhat from those of the ATW Team A crucial assumption was the consumption of the plutonium in a resctor, which would be more dificult politically than technically. However, the step of separating the spent fuel (Figure 7) is the larger issue, so the step that enables aTW approach could slso casble recycling of the plutonium into reactors.

Once the phitonium is climinated from the feed-stream, the waste burner looks much different. The minor actinides will fission in a fast neutronic spectrum, although the mass will be subcritical. Also, there will be excess neutrons from converting long-lived fission products, although probably to few to convert all the iodine- 129 . There would be few if any for converting technicium-99, although that material could be safely converted in reactors (control rods?).

The Phoenix Concept is illustrated in Figure 9. The machine resembles a loop type fast spectrum reactor, complete with a power conversion system which provides more than enough electricity to power the accelerator. (This ability to generate excess electricity sometimes seems paradoxical, but the error is in assuming that nuclear "waste" contains no energy.) There are 9 modular target modules, with cach resembling the Fast Flux Test Facility (FFTF) (Weatinghouse Henford Company, 1975). However, in this case the fuel is made of Americium-Neptunium-Curium oxide. The throughputs for the machine are indicated in the figure. The criticality of the machine begins near 0.7 , and climbs into 0.9 range within a couple of 2 year operating cycles.

\section{THE OMRGA PROJECT}

While ATW may be the most ambitious accelerator waste transmutation effort, the Japanese OMEGA Project (Takizuka, 1994) is the most ambitious in terms of putting a system like that illustrated in Figure 7 into reality. Various options are under consideration, including more than one accelerator target. The target shown in Figure 10 bears some resemblance to both ATW andPHOENIX. Like ATW, the beam enters the vessel from above and strikes a spallation target (tungsten rather than lead) in the center of the vessel. Also, the fuel contains some plutonium to add to the neutron multiplication. But, like PHOENIX, the fivel is solid and the spectrum is fast. In addition to the target in Figure 10, OMEGA includes a molten-salt target and some exotic options for transmuting cesium and strontium.

THE ENLRGY AMPLIMR

Rubbia (Rubbia, 1994) has recently been a strong advocate of a 
proliferation resistant accelerator-driven breeder reactor which he describes as an "energy-amplifier". In this case it is thorium that is the base fuel, although much of the fission takes place in the uranium-233 that is created when the thorium-232 captures a neutron. Plutonium production is minimized, with the trace quantities posing little proliferation hazard. In principle, one could divert the Uranium-233, although this material is radioactive enough to create handling problems, and one can always blend the U-233 down using natural uranium.

With respect to the accelerator-driven aspect of the "EnergyAmplifier", this allows one to begin the cycle with low system reactivity and to accommodate significant reactivity swings during machine operation. In principle, it resembles early acceleratorbreoder concepts, although in this case it is a proliferation-resistant fuel cycle that is the objective. While the design principles of the machine are quite feasible, the proposed scope of this approach is ambitious.

\section{SUMMARY}

The concurrent technology developments in the accelerator field and the discouraging prospects for the construction of new nuclear reactors in the U.S. for any purpose has set up an opportunity for applications of accelerator technology and spallation targets. Many of the concepts described herein are technically feasible, as are many of the ideas being discussed less formally. The question of conomic viability is far more troublesome, and one must establish more than the fact that it is "not- a-reactor" that is being proposed. Certainly the economics of the technology will improve as superconducting niobium cavities and niobium-based magnets become more common, and as higher efficiency AC-to-RF power tubes (kystrons) become available. There remain some open safety issues, especially when actinides are in the target region.

The technology is within our grasp to produce enough neutrons to compete with large research reactors and small power reactors. And, as discussed in this paper, there are many important missions that can be achieved successfully using these large "sledge-hammex" accelerators. It seems no longer a question of whether such a machine will be built, but rather a question of when and for which mission (s)?

\section{REFERENCES}

Kouts, H. and Steinberg, M, Eds., Proceedings Information Meeting on Acoelerator Breding, Upton, NY, January 18-19, 1977 , BNL-50838, Brookhaven National Laboratory, 1978.

Humphries, Stanley, Jr., Principles of Charged Particle Acceleration. John Wiley \& Sons, New York, 1986.

Wangler, T.P., et.al, "Linear Accelerator for Production of Tritium: Physics Design Challenges", Proc. 1990 Linear Accelerator Conference, Albuquerque, NM, September 1990, pp. 548-552.
Lawrence, George P., "Los Alamos High-Power Proton Linac Designs", Proceedings of the American Institute of Physics Conference 346, International Conference on Accelerator-Driven Transmutation Technologies and Applications, Las Vegas, NV, July 1994.

Deleyan, J.R. and Bohn, C.L., "Overview of Supercoducting RF Technology and its Application to High-Current Linscs", Proceedings of the Americen Institute of Physics Conference 346, International Conference on Accelerator-Driven Transmutation Technologies and Applications, Las Vegas, NV, July 1994.

Klein, H. "Linac Design for the European Spallation Source," Proceedings of the American Institute of Physics Conference 346, International Conference on Accelerator-Driven Transmutation Technologies and Applications, Las Vegas, NV, July 1994.

Rubbia, Carlo, "A High Gain Energy Amplifier Operated with Fast Neutrons", Proceedings of the American Institute of Physics Conference 346, International Conference on Accelerator-Driven Transmutation Technologies and Applications. Las Vegas, NV, July 1994.

Russell, G.J., Pitcher, E.J., and Daemen, L.L., "Introduction to Spallation Physics and Spallation-Target Design," Proceedings of the American Institute of Physics Conference 346, International Conference on Accelerator-Driven Transmutation Technologies and Applications, Las Vegas, NV, July 1994.

Selby, D.L., et.al, "Advanced Neutron Source Research and Development Plan," Oak Ridge National Laboratory Report, ORNL/TM-12249, Nov. 1992.

Todosow, M. and Ludewig, H., Brookhaven National Laboratory, "5 MW Spallation Neutron Source: Preconceptual Design Study," BNL 60678, June 1994.

Cappiello, M. et.al., "Target/Blanket Design for the Los Alamos APT System," Proceedings of the American Institute of Physics Conference 346, International Conference on Accelerator-Driven Transmutation Technologies and Applications, Las Vegas, NV, July 1994.

U.S. General Accounting Office Repart, "Nuclear Science: DOE'S Self-Supporting Isotope Program Is Experiencing Problems," GAORCED-92-122FS, June 1992.

Brager, H.R, et.al., "Physics of Plutonium-238 Production in the Fast Flux Test Facility for the Space Isotope Program," Westinghouse Hanford Company Report, WHC-SP-0486, June 1989.

Van Tuyle, G.J., et.al., "Accelerator-Driven Subcritical Target 
Concept for Transmutation of Nuclear Wastes," Nuclear Technology, Vol. 101, pp 1-17, Jan. 1993.

Bimey, S.E., et.al., "CURE: Clean Use of Reactor Energy, "WHCDP-0268, Westinghouse Hanford Company, May 1990.

Bowman, C.D., et.al., "Nuclear Power Generation and Waste Transmutation Using an Accelerator-Driven Intense Thermal Neutron Source," Nuclear Instruments and Methods in Physics Research (Sec. A), Vol A320, Nos. 1, 2, August 15, 1992, pp 336367.

"Final Safety Analysis Report for the Fast Flux Test Facility," HEDL-TI-75001, Westinghouse Hanford Company, Dec. 1975.

"Takizuka, T., et.al, "JAERI R\&D on Accelerator-Based Transmutation under OMEGA Programs," Proceedings of the American Institute of Physics Conference 346, International Conference on Acceleratar-Driven Transmutation Technologies and Applications, Las Vegas, NV, July 1994.

\section{DISCLAIMER}

This report was prepared as an account of work sponsored by an agency of the United States Government. Neither the United States Government nor any agency thereof, nor any of their employees, makes any warranty, express or implied, or assumes any legal liability or responsibility for the accuracy, completeness, or usefulness of any information, apparatus, product, or process disclosed, or represents that its use would not infringe privately owned rights. Reference herein to any specific commercial product, process, or service by trade name, trademark, manufacturer, or otherwise does not necessarily constitute or imply its endorsement, recommendation, or favoring by the United States Government or any agency thereof. The views and opinions of authors expressed herein do not necessarily state or reflect those of the United States Government or any agency thereof. 


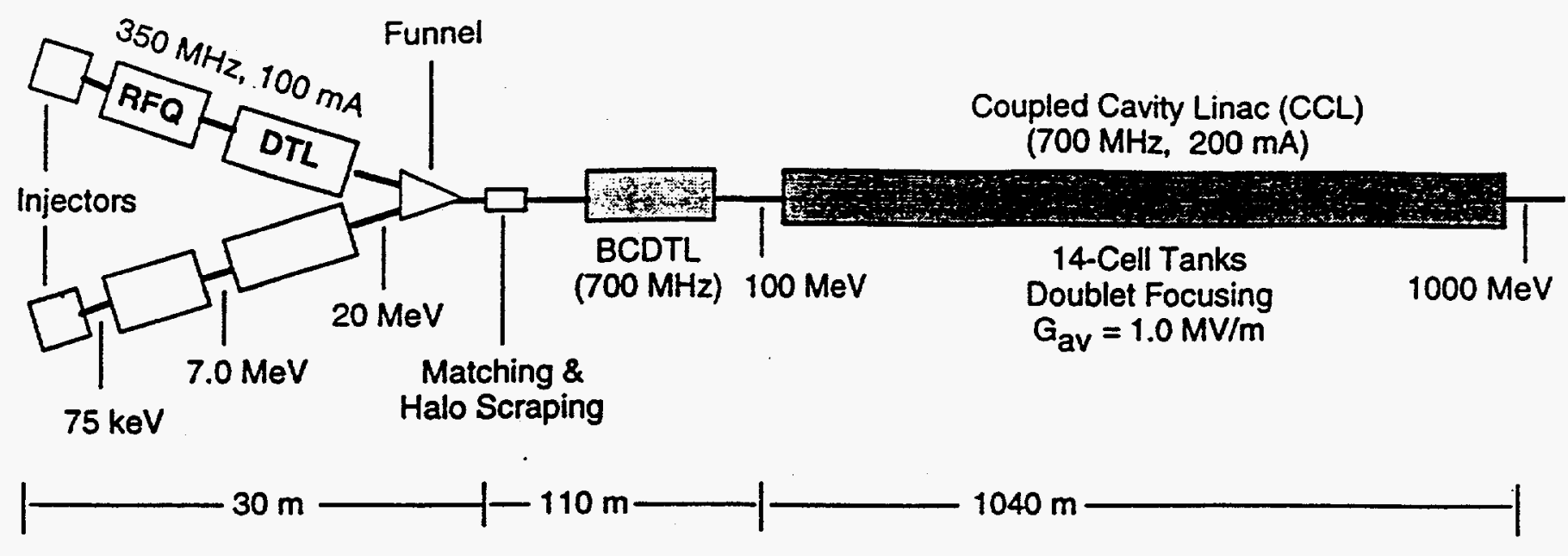

Figure 1. Reference Concept for Funneled 1-GeV, 200-mA Linac

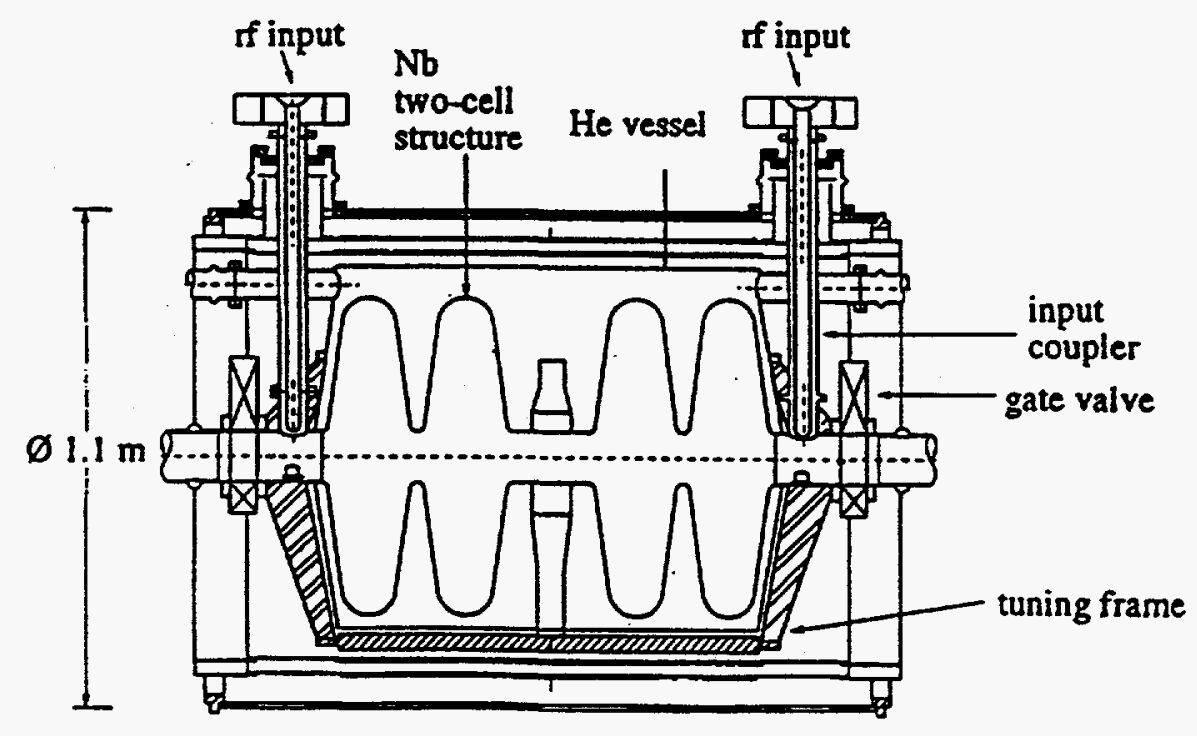

Figure 2. Schematic Drawing of a Possible Superconducting Accelerator Module 


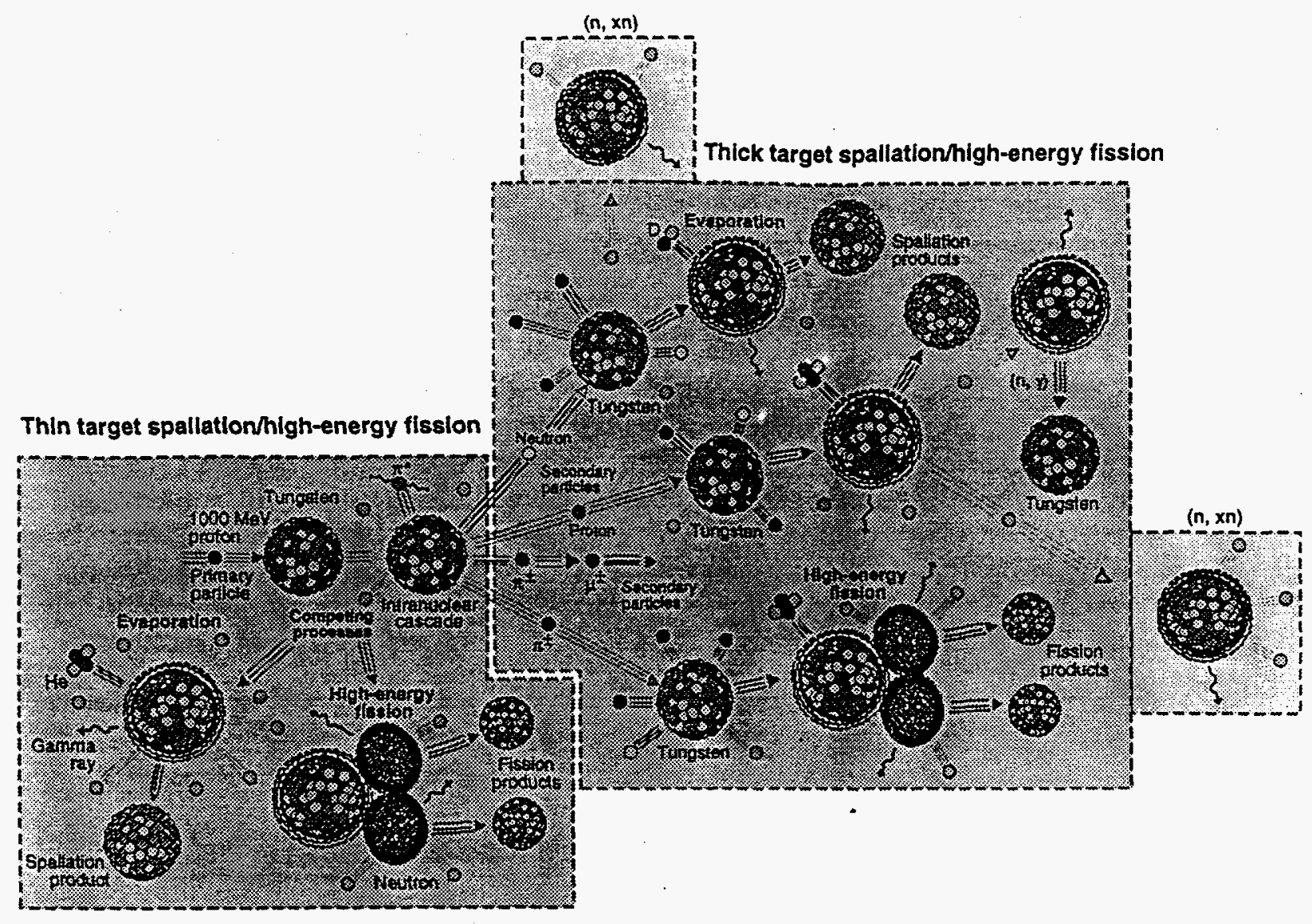

Figure 3. Illustration of the Spallation Process in Thick Targets, with Evaporation Competing with High-Energy Fission in the De-Excitation of Highly-Excited Nuclei

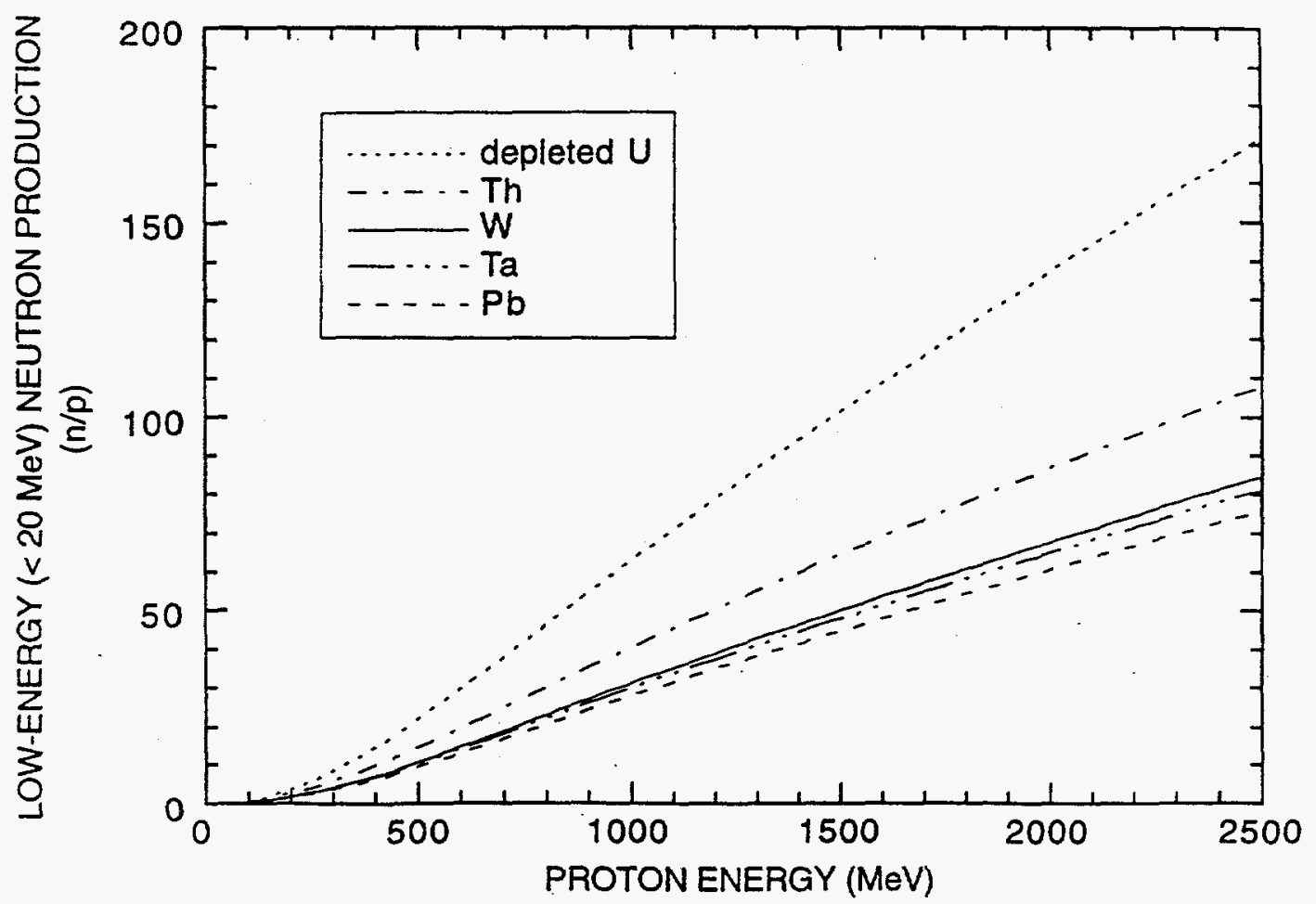

Figure 4. Production of Low-Energy Neutrons as a Function of Incident Proton Energy for Various Target Materials. The Targets are 50-cm-diam x 200-cm-long Right-Circular Cyclinders; the Protons are Incident on the Cylindrical Axis. 


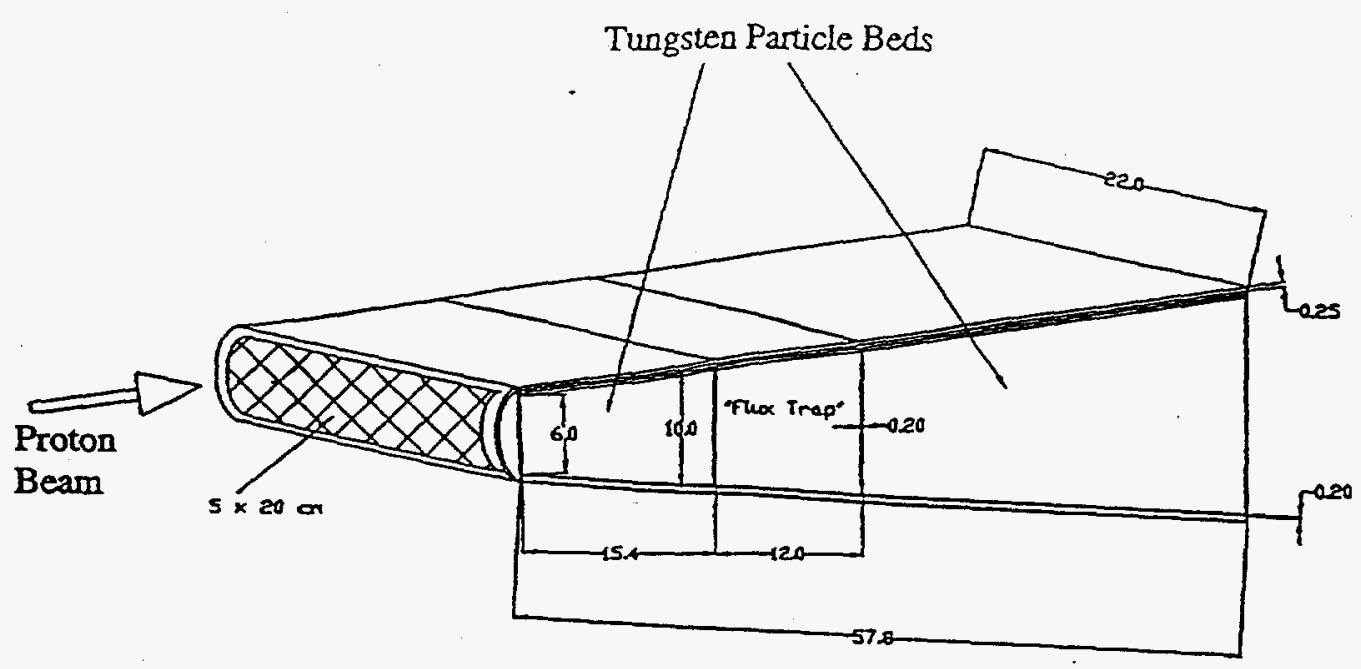

Figure 5. Two Bed Target

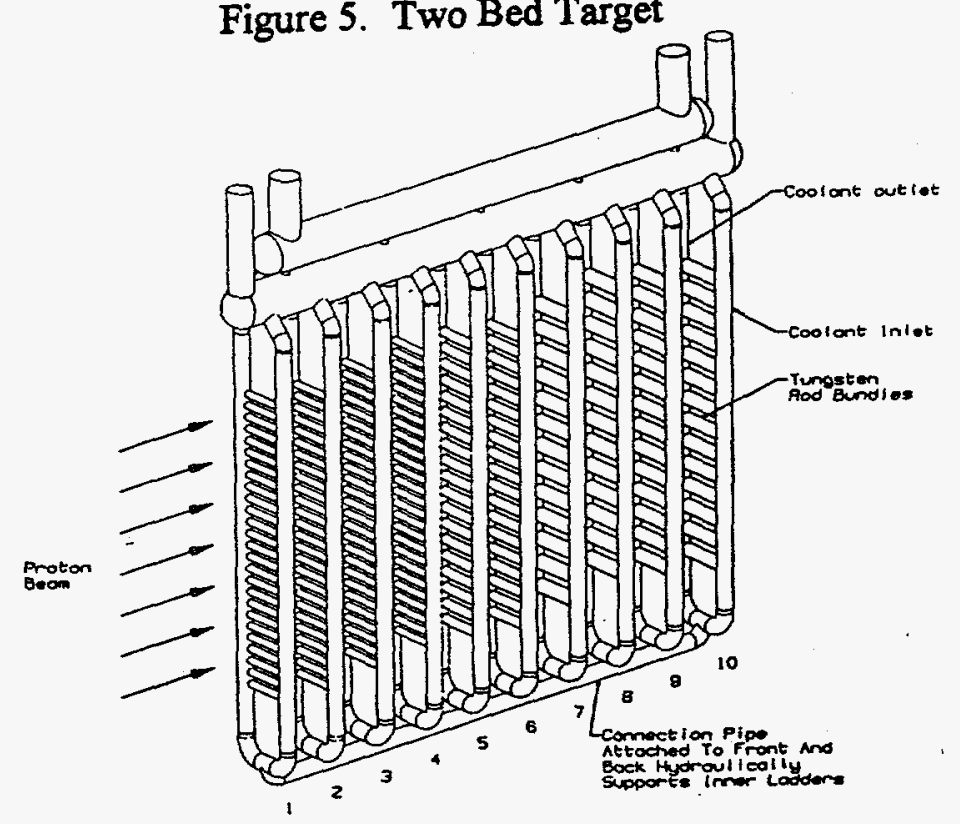

Figure 6. Tungsten Neutron Source Region for the Accelerator Production of Tritium

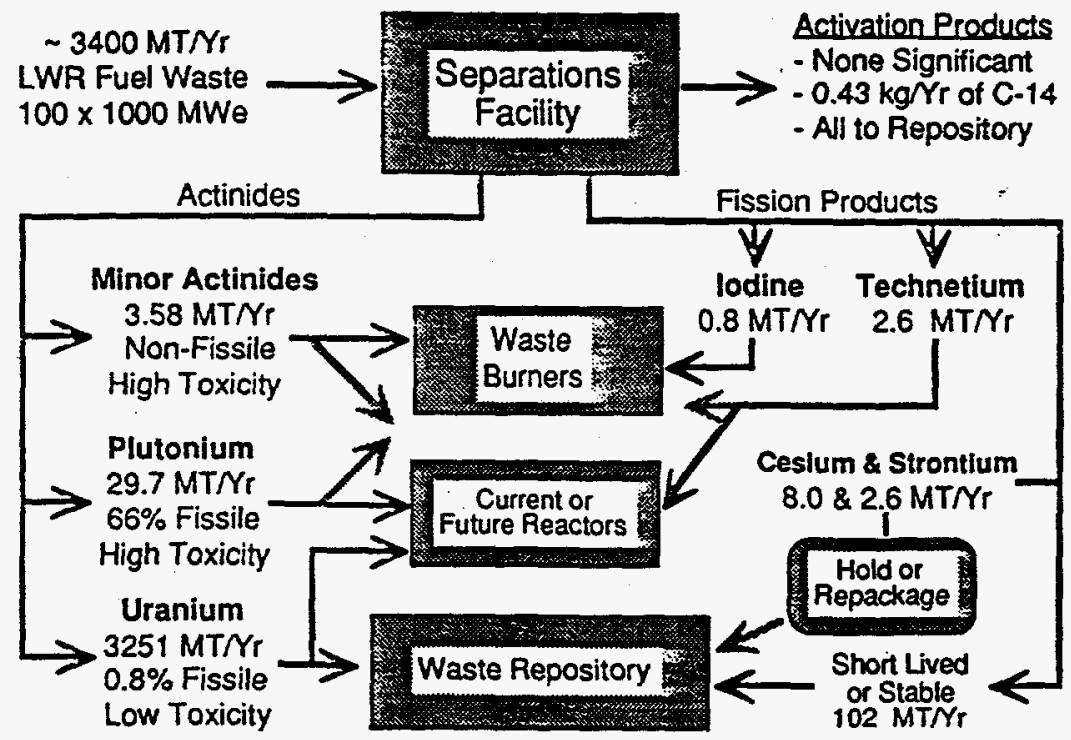

Figure 7. Approximate Mass Flow from 100 LWRs (Predicted, Not Measured) 


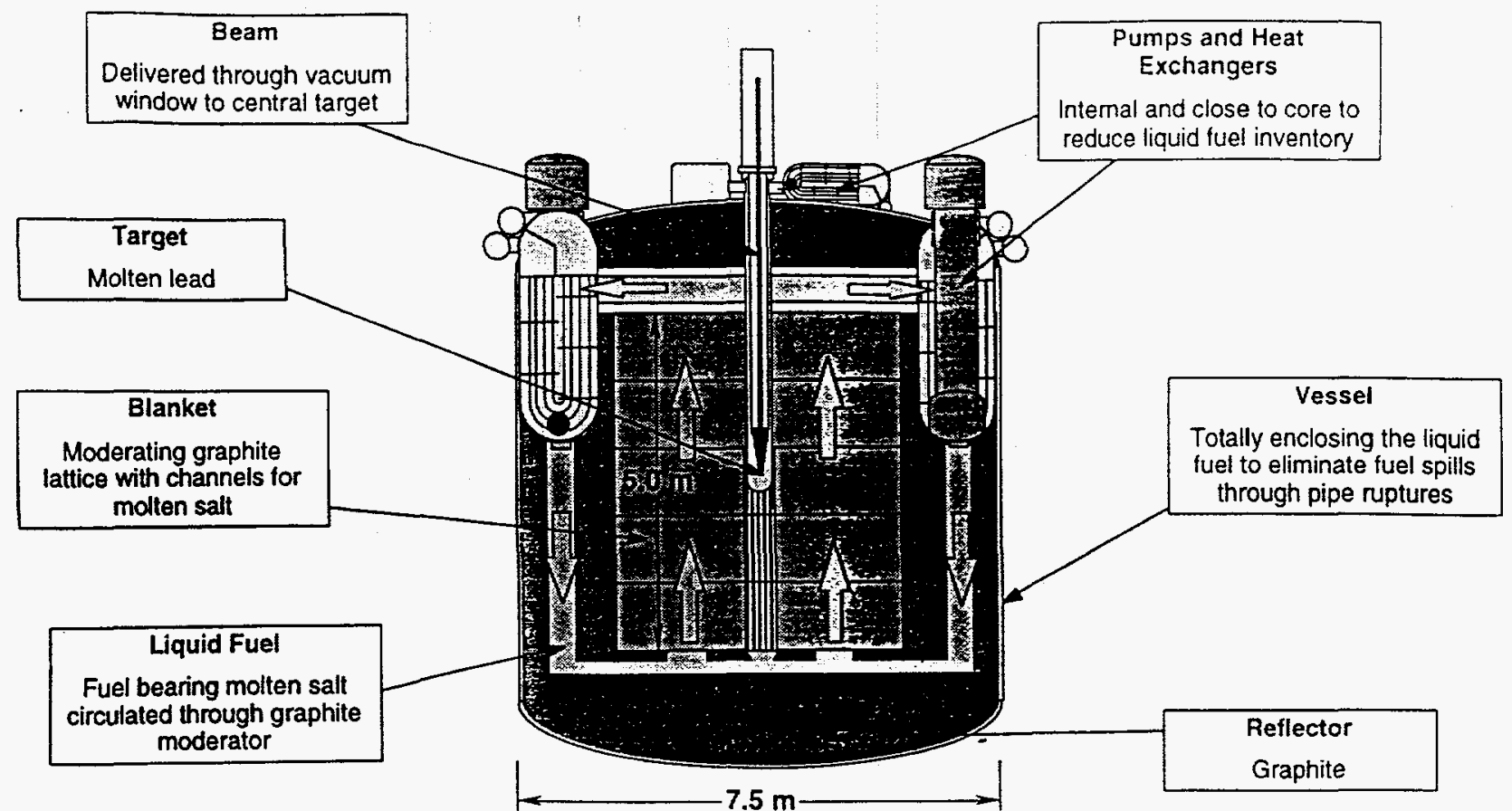

Figure 8. The prototype $500 \mathrm{MWt}$ ADTT molten salt blanket. This blanket can be used for all the ADTT applications (ADEP, ATW, ABC). Graphite-moderated and fueled by molten salt, the ADTT blanket improves on the 1960's Oak Ridge molten salt reactor concept, by incorporating the many design improvements introduced by the newer liquid-metal reactors "pool" designs.

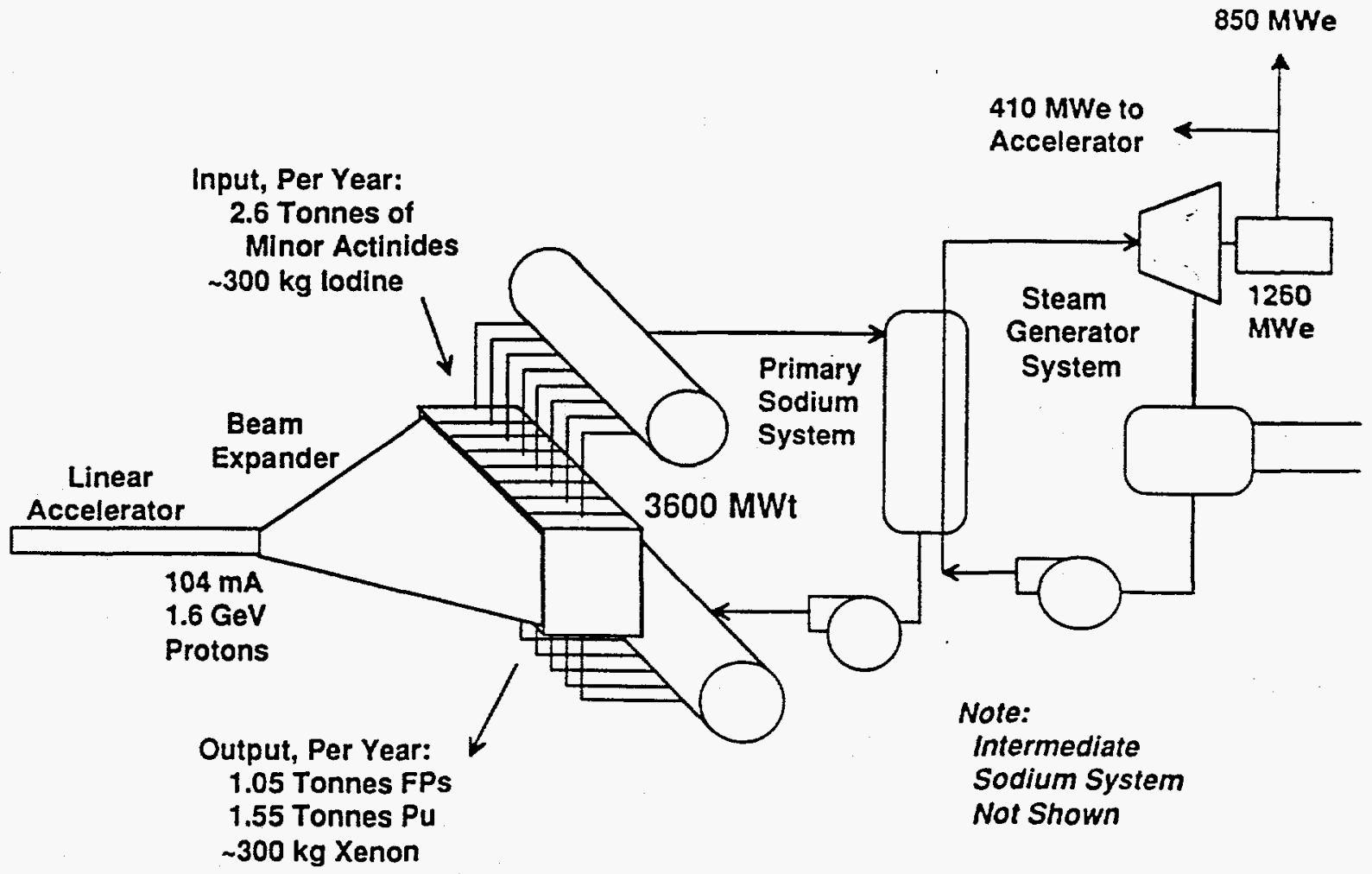

Figure 9. The PHOENIX Concept 